\title{
A modified exponential model for reported death toll during earthquakes*
}

\author{
Xinyan $\mathrm{Wu}$ and Jianhua $\mathrm{Gu}^{*}$ \\ Institute of Geophysics, China Earthquake Administration, Beijing 100081, China
}

\begin{abstract}
Reliable earthquake death toll estimate can provide valuable references for disaster relief headquarters and civil administration departments to make arrangement and deployment plan during post-earthquake relief work, thus increasing the efficiency of the relief work to a certain extent. In this study, we acquired the death toll data of Wenchuan earthquake, fitted the data using modified exponential curve and compared the result with that of the exponential function. Experimental verification with Chi-Chi earthquake and Kobe earthquake data shows that the fitted result by modified exponential curve is more satisfactory. The final death toll resulting from future destructive earthquakes can be estimated by the acquired fitting function.
\end{abstract}

Key words: earthquake; death toll; modified exponential curve

CLC number: P315.01 Document code: A

\section{Introduction}

Reducing the casualties is an important goal of the work of earthquake prevention and disaster reduction. Many experts and scholars in China and abroad have carried out explorative research on the law of earthquake death toll. Lomnitz (1970) studied the relationship between occurring time and final death toll of $22 M 7$ to M8 earthquakes occurred in Chile from 1570 to 1960. Christokov and Samardjieva (1984) put forward a relationship between death toll and population density and magnitude. Samardjieva and Oike (1992) and Wyss (2005) separately made statistical on data of earthquake death toll for Japan and Himalaya region. Fu et al (1993) had also studied relationship between earthquake death toll and magnitude and occurring time, but he didn't concern about the time history of the reported death toll from an earthquake.

Since 1995, the time history of the reported death toll from an earthquake has been studied by a number of scholars and gratifying progress has been made. Hong et al (1995) made an analysis and induction about the death toll and building damage from the Hyogo-ken Nanbu, Japan, earthquake; After studying the damage of

\footnotetext{
* Received 10 December 2008; accepted in revised form 12 January 2009; published 10 April 2009.

Contribution No. 09FE3002, Institute of Geophysics, China Earthquake Administration.

• Corresponding author.e-mail: jh.gu@263.net
}

Kobe earthquake and Lijiang earthquake in Yunnan province, China, Wang and Yang (1997) found that the death tolls from the earthquakes varied with time, and pointed out the significance of time history curve in disaster response and decision making; Gao and Jia (2005) normalized the reported death tolls of dozens of earthquakes, fitted the time-dependent variation in the reported death tolls by quartic polynomial and satisfactorily fitted the relation between earthquake death toll and time after the quake, though the physical significance of the model is uncertain; Liu and $\mathrm{Wu}$ (2006) suggested using an exponential model to describe the relation between earthquake death toll and time after the quake.

Based on the death toll data of Wenchuan earthquake collected after the quake, we studied the relation between the number of fatalities $(N)$ reported after the event and time $(t)$, and obtained a satisfactory result. The method can be used to rapidly estimate the time-related variation in death toll after a strong earthquake, providing references for directing disaster relief work and deploying rescue teams.

\section{Data source}

The $M_{\mathrm{S}} 8.0$ earthquake, which hit Wenchuan county, Sichuan province at 14:28:04 on May 12, 2008, has caused heavy casualties and property losses to Sichuan and neighboring provinces. Following the quake, we promptly collected the death toll data released by the 
State Council Information Office and State Council Earthquake Disaster Relief Headquarters (Table 1), and acquired a curve of the number of deaths reported before June 2, 2008, versus time (Figure 1).

Figure 1 shows that $N$ increases with $t$, reaching
$90 \%$ of the finally reported figure in two weeks, by June $2, N$ is very close to the current official figure (excluding those missing) and the growth rate slows down to near zero.

Table 1 Number of reported deaths after Wenchuan earthquake (up to June 2, 2008)

\begin{tabular}{|c|c|c|c|c|c|c|c|}
\hline No. & Time & $\begin{array}{l}\text { Hours after the } \\
\text { shock } t / \mathrm{h}\end{array}$ & $\begin{array}{c}\text { Number of } \\
\text { deaths } N\end{array}$ & No. & Time & $\begin{array}{l}\text { Hours after the } \\
\text { shock } t / \mathrm{h}\end{array}$ & $\begin{array}{c}\text { Number of } \\
\text { deaths } N\end{array}$ \\
\hline 1 & 16:00, May 12 & 1.5 & 4 & 15 & 12:00, May 21 & 213.5 & 41353 \\
\hline 2 & 18:00, May 12 & 3.5 & 107 & 16 & 10:00, May 22 & 235.5 & 51151 \\
\hline 3 & 21:00, May 12 & 6.5 & 157 & 17 & 19:00, May 22 & 244.5 & 55239 \\
\hline 4 & 22:00, May 12 & 7.5 & 592 & 18 & 12:00, May 23 & 261.5 & 55740 \\
\hline 5 & $22: 50$, May 12 & 8.3 & 8533 & 19 & 12:00, May 24 & 285.5 & 60560 \\
\hline 6 & 17:00, May 13 & 26.5 & 11921 & 20 & $12: 00$, May 25 & 309.5 & 62664 \\
\hline 7 & 19:00, May 13 & 28.5 & 12012 & 21 & $12: 00$, May 26 & 333.5 & 65080 \\
\hline 8 & $14: 00$, May 14 & 47.5 & 14866 & 22 & $12: 00$, May 27 & 357.5 & 67183 \\
\hline 9 & 16:00, May 15 & 73.5 & 19500 & 23 & $12: 00$, May 28 & 381.5 & 68109 \\
\hline 10 & 14:00, May 16 & 95.5 & 22069 & 24 & 12:00, May 29 & 405.5 & 68516 \\
\hline 11 & 14:00, May 17 & 119.5 & 28881 & 25 & 12:00, May 30 & 429.5 & 68858 \\
\hline 12 & 14:00, May 18 & 143.5 & 32477 & 26 & 12:00, May 31 & 453.5 & 68977 \\
\hline 13 & 16:00, May 19 & 169.5 & 34073 & 27 & 12:00, June 1 & 477.5 & 69016 \\
\hline 14 & 18:00, May 20 & 195.5 & 40075 & 28 & 12:00, June 2 & 501.5 & 69019 \\
\hline
\end{tabular}

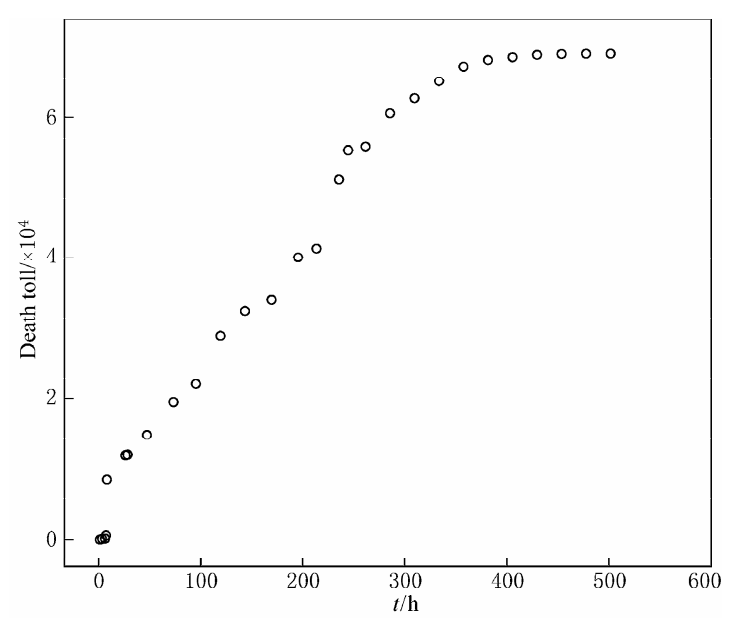

Figure 1 Time history of the reported deaths during Wenchuan earthquake.

\section{Method}

Liu and $\mathrm{Wu}$ (2006) proposed using an exponential model to describe the relation between the number of deaths from an earthquake and time after the quake, and believed that the larger the number of unfound deaths is, the easier it will be to find more deaths. Let $N_{0}$ be the final number of deaths, then $N_{0}-N$ is the number of unfound deaths. If the disaster relief efficiency is a constant, $\alpha$, then $\alpha\left(N_{0}-N\right)$ is the number of deaths found in one unit of time, i.e.

$$
\frac{\Delta N}{\Delta t}=\alpha\left(N_{0}-N\right)
$$

By finding the primitive function of the above equation, we get the relation between $N$ and $t$

$$
N=N_{0}\left(1-\mathrm{e}^{-a t}\right) .
$$

The resultant time history curve of the reported deaths from 21 earthquakes in China and abroad (Gao and Jia, 2005) shows that the death toll rises rapidly within the first few days after the quake. With the passing of time and deepening of relief work, the possibility of finding survivors phases down and the growth rate of death toll slows down to saturation value. This pattern is reflected by the variation curve of death tolls at different times after the Wenchuan earthquake shown in Figure 1, though the maximum growth rate appears at $235.5 \mathrm{~h}$ after the quake instead of at the first few time points. In view of such an extremely huge earthquake, the above phenomenon is justifiable. As traffic and communications were cut off after the earthquake, it was impossible to report all the casualties to higher authorities within a short period of time, and the official figures released in the first few days could only involve damage and losses of some of the disaster-hit areas. Only after all-around rescue operations were carried out by large numbers of relief teams in the hard-hit areas, could the casualty figures be completely presented.

The above rule is completely in conformity with the phenomenon described by modified exponential curve in the long-term time series prediction model, therefore, we can fit the relation between $N$ and $t$ using 
this curve.

$$
N=N_{0}+a \cdot b^{t},
$$

where $N_{0}, a$ and $b$ are unknown constants, $N_{0}>0, a \neq 0$, $0<b \neq 1 . N_{0}$ is the final number of possible deaths, and $b$ is the average growth rate.

In fact, equation (2) is a specific form of equation (3) and equation (3) is the generalization of equation (2). Equation (3) takes $b$ while equation (2) takes $\mathrm{e}^{-\alpha}$ as the base. In equation (3), all the three coefficients are to be determined by the sequence of number itself, and they obviously approximate the data more closely than those in equation (2).

As $N_{0}, a$ and $b$ are unknown, the 3-sum algorithm in statistics is suitable for equation (3) (Jia, 2006). By the so-called 3-sum algorithm, the observed data are divided equally into three sections (each containing $n$ data), summation is performed for each section and then the three equations, each of which contains three unknown parameters, are solved. The expressions for the parameters are as follows:

$$
\left\{\begin{array}{l}
b=\left(\frac{S_{3}-S_{2}}{S_{2}-S_{1}}\right)^{\frac{1}{n}} \\
a=\left(S_{2}-S_{1}\right) \frac{b-1}{b\left(b^{n}-1\right)^{2}}, \\
N_{0}=\frac{1}{n}\left(S_{1}-1 \frac{a b\left(b^{n}-1\right)}{b-1}\right)
\end{array}\right.
$$

where $S_{1}, S_{2}$ and $S_{3}$ are the total sums of the observed values, respectively.

Following is the fitting and comparison of the death toll from Wenchuan earthquake using the two methods respectively.

\section{Results}

\subsection{Fitted result by exponential function}

Based on Wenchuan earthquake death toll data as of June 2, we carried out computation with SPSS15.0 statistical software and got the following exponential model:

$$
N_{\text {Wenchuan }}=N_{0}\left(1-\mathrm{e}^{-a t}\right),
$$

where $N_{0}$ and $a$ have their errors of $88877 \pm 11557$ and $(0.004 \pm 0.0005) \mathrm{h}$, respectively, at $95 \%$ confidence level.

Substituting $t=717.5$ into the model, we get the predicted death toll figure of 81663 at 12:00 on June 11, as compared with the actual figure of 69146 , the relative error being $18 \%$.

Using the death toll data as of May 21, we would get the errors $51993 \pm 17447$ and $0.007 \pm 0.004 / \mathrm{h}$ for $N_{0}$ and $a$, respectively, at 95\% confidence level.

Substituting $t=717.5$ into the model, we get the predicted death toll figure of 51651 at 12:00 June 11, nearly 20000 fewer than the actual fatalities, the relative error being $-25 \%$.

\subsection{Fitted result by modi fied exponential curve}

Data fitting for Wenchuan earthquake using modified exponential curve requires equal interval between time points of the death toll figure. Figure 1 shows the time interval of most data from two days after the quake is around 24 hours. In order to maintain consistency of the cut-off time, we conducted data processing by linear interpolation, and $\Delta t=24$. The 21 data are divided equally into 3 sections, $n=7$. Table 2 displays the interpolated death toll from Wenchuan earthquake and

\begin{tabular}{|c|c|c|c|c|c|c|c|}
\hline No. & $\begin{array}{l}\text { Hours after the } \\
\text { shock } t / \mathrm{h}\end{array}$ & $\begin{array}{l}\text { Number of deaths } \\
\text { after interpolation } N\end{array}$ & $\begin{array}{c}\text { First-order difference } \\
\text { link relative }\end{array}$ & No. & $\begin{array}{l}\text { Hours after the } \\
\text { shock } t / \mathrm{h}\end{array}$ & $\begin{array}{l}\text { Number of deaths } \\
\text { after interpolation } N\end{array}$ & $\begin{array}{c}\text { First-order difference } \\
\text { link relative }\end{array}$ \\
\hline 1 & 21.5 & 11149 & & 12 & 285.5 & 60560 & 1.309 \\
\hline 2 & 45.5 & 14565 & & 13 & 309.5 & 62664 & 0.437 \\
\hline 3 & 69.5 & 18638 & 1.192 & 14 & 333.5 & 65080 & 1.148 \\
\hline 4 & 93.5 & 21856 & 0.790 & $S_{2}$ & & 376331 & \\
\hline 5 & 117.5 & 28313 & 2.007 & 15 & 357.5 & 67183 & 0.870 \\
\hline 6 & 141.5 & 32176 & 0.598 & 16 & 381.5 & 68109 & 0.440 \\
\hline 7 & 165.5 & 34073 & 0.491 & 17 & 405.5 & 68516 & 0.440 \\
\hline$S_{1}$ & & 160770 & & 18 & 429.5 & 68858 & 0.840 \\
\hline 8 & 189.5 & 38875 & 2.531 & 19 & 453.5 & 68977 & 0.348 \\
\hline 9 & 213.5 & 41353 & 0.516 & 20 & 477.5 & 69016 & 0.328 \\
\hline 10 & 237.5 & 52059 & 4.320 & 21 & 501.5 & 69019 & 0.077 \\
\hline 11 & 261.5 & 55740 & 0.344 & $S_{3}$ & & 479678 & \\
\hline
\end{tabular}
first-order difference link relative.

Table 2 Number of deaths from Wenchuan earthquake after interpolation and analytical data 
By calculating first-order difference link relative of the death toll at each time point, we found that the number fluctuates invariably around a constant, suggesting rationality of the modified exponential curve model.

Substituting relevant data into the above equation yields:

$$
\left\{\begin{array}{l}
b=0.900 \\
a=-88085, \\
N_{0}=82123
\end{array}\right.
$$

Then we have the modified exponential model of the death toll from Wenchuan earthquake

$$
N=82123-88085 \times 0.900^{t} .
$$

By calculating the predicted value and relative error $\varepsilon_{t}$ of each time point using the above model, we get the mean absolute percentage error $\bar{\varepsilon}$ for examining predictive validity of the model:

$$
\bar{\varepsilon}=\frac{1}{21} \sum_{t=1}^{21} \frac{\left|\varepsilon_{t}\right|}{N_{t}} \times 100 \%=10 \% .
$$

The result defines $\bar{\varepsilon}$ as $10 \%$, indicating that precision of the model prediction has reached certain extent and the model can be used for trend projection.

Substituting $t=30$ into the model, we get the predicted death toll figure of 78389 at 12:00 on June 11, as compared with the actual figure of 69146 , the relative error being $13 \%$.

In practical use of the method, we could put fewer data in the model, so as to predict the possible death toll in three weeks or even in one month. Let's take the data before May $21(n=3)$ as an example. After calculation, we obtain the following modified exponential model of death toll:

$$
N=94486-89348 \times 0.944^{t},
$$

where $\overline{\mathcal{E}}$ is $8 \%$, which is also within the permissible range.

Substituting $t=30$ into the model, we get the predicted death toll figure of 78628 at 12:00 on June 11, the relative error being $13.7 \%$.

Figures 2 and 3 show the fitted versus actual numbers of deaths from Wenchuan earthquake using exponential function and modified exponential curve respectively. The fitted results and relative errors by the two methods show the fewer data used in fitting, the larger the relative error of the estimated death toll; the more data used (i.e. the later the cut-off time), the closer the estimated number to the actual figure. This is consistent with the actual situation.

\section{Comparative analysis of Chi-Chi and Kobe earthquakes}

In order to illustrate the feasibility of the fitting methods of modified exponential curve and exponential function, we made a comparison by adding the data of Chi-Chi (Shi, 2006) and Kobe (Hong, 1995) earthquakes. Table 3 lists the fitted numbers of deaths from all three

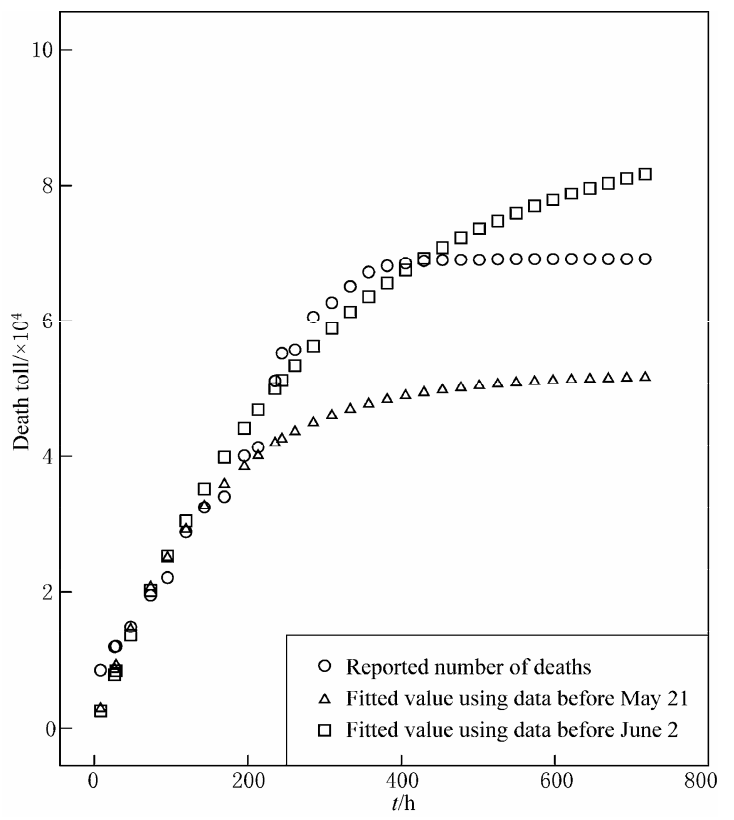

Figure 2 The fitted versus actual numbers of deaths from Wenchuan earthquake using exponential function.

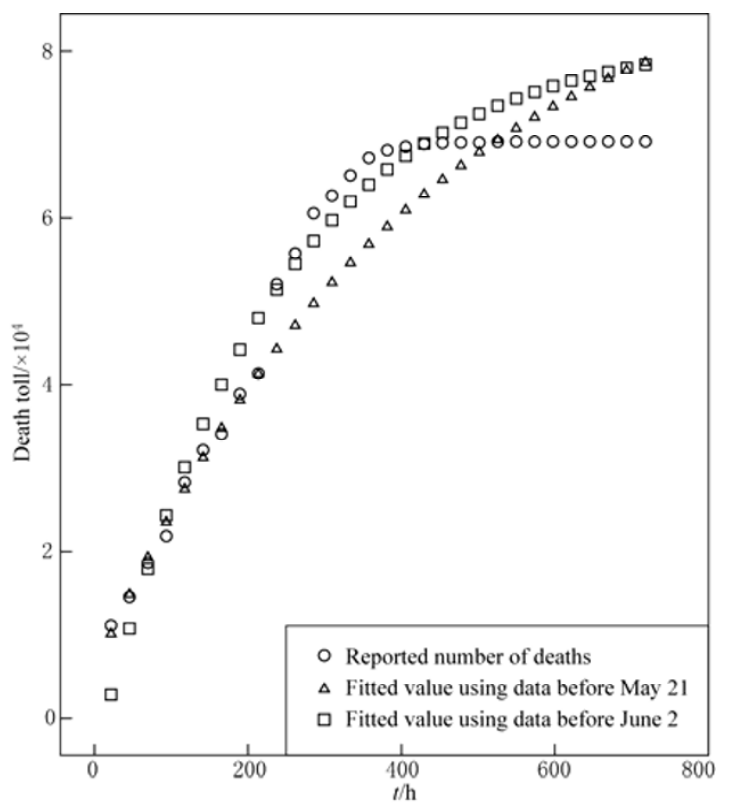

Figure 3 The fitted versus actual numbers of deaths from Wenchuan earthquake using modified exponential curve. 
earthquakes respectively using the two functions and the inspection results. Figures 4 and 5 display the fitted versus actual numbers of deaths from Chi-Chi and Kobe earthquakes respectively, using modified exponential curve.

Table 3 Fitted numbers of deaths for all three earthquakes using the two functions and the inspection results.

\begin{tabular}{|c|c|c|c|c|c|c|c|c|c|c|}
\hline \multirow{2}{*}{ Events } & \multirow{2}{*}{$N$} & \multicolumn{4}{|c|}{ Fitted parameters by exponential function and inspection results } & \multicolumn{5}{|c|}{ Fitted parameters by modified exponential curve and inspection result } \\
\hline & & $N_{0}$ & $\alpha / h$ & $\bar{\varepsilon}$ & $\varepsilon_{t}$ & $N_{0}$ & $a$ & $B$ & $\bar{\varepsilon}$ & $\varepsilon_{t}$ \\
\hline Wenchuan & 69146 & $88877 \pm 11557$ & $0.004 \pm 0.0005$ & $12 \%$ & $18 \%$ & 82123 & -88085 & 0.900 & $10 \%$ & $13 \%$ \\
\hline Chi-Chi & 2079 & $2040 \pm 74$ & $0.059 \pm 0.009$ & $3.9 \%$ & $-2.16 \%$ & 2055 & -1353 & 0.728 & $4.8 \%$ & $-2.07 \%$ \\
\hline Kobe & 5102 & $5209 \pm 137$ & $0.019 \pm 0.001$ & $10.5 \%$ & $2 \%$ & 5097 & -7078 & 0.708 & $5 \%$ & $-0.078 \%$ \\
\hline
\end{tabular}

Note: Data up to June 2; relative error $\varepsilon_{t}$ refers to error between the estimated number and actual figure at 12:00, June 2.

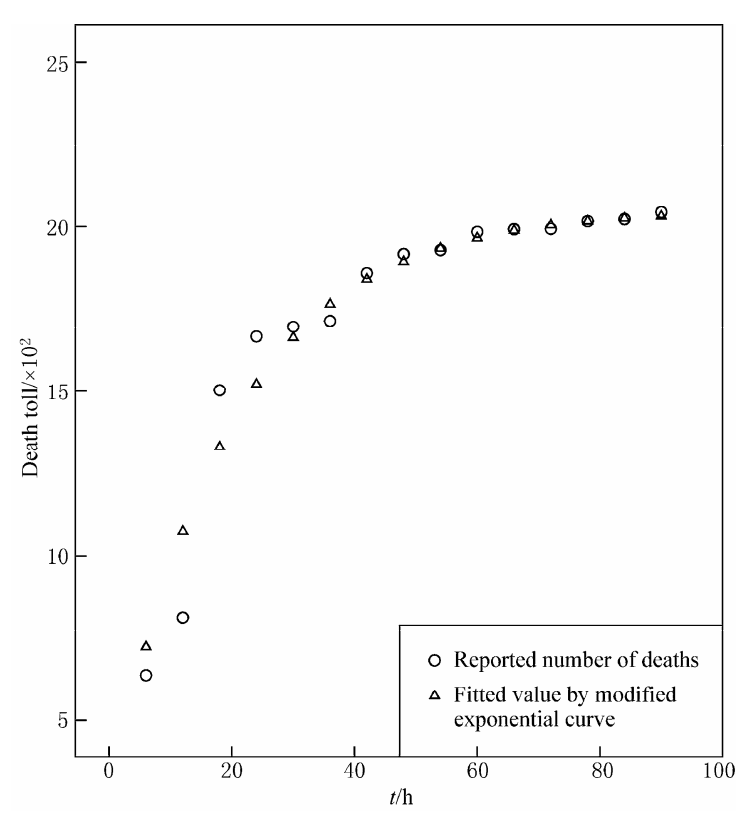

Figure 4 The fitted versus actual numbers of deaths from Chi-Chi earthquake using modified exponential curve.

As regards relative errors between estimated and actual numbers of deaths for all three earthquakes, the relative error between the fitted result and actual figure given by modified exponential curve is much smaller than that given by exponential function, and the mean absolute percentage error $\bar{\varepsilon}$ of two of the earthquakes (without Chi-Chi) obtained by exponential function is remarkably higher than that obtained by modified exponential curve. Both indicate that modified exponential curve features higher precision than exponential function.

Table 3, Figures 4 and 5 comprehensively show that modified exponential curve is more applicable to earthquake death toll estimation than exponential function.

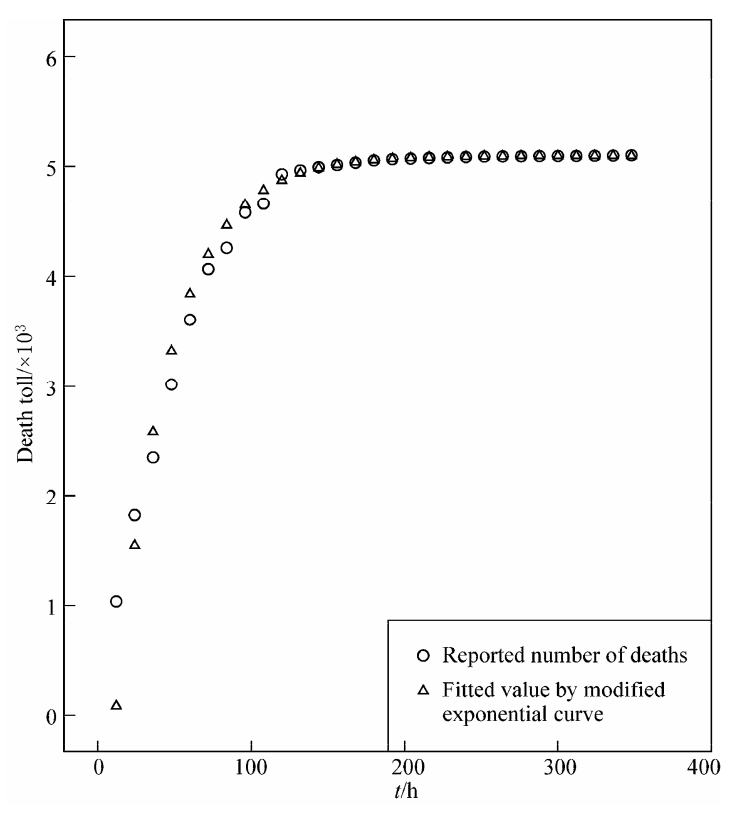

Figure 5 The fitted versus actual numbers of deaths from Kobe earthquake using modified exponential curve.

\section{Discussion and conclusions}

Modified exponential curve fitting method is applicable to death toll estimation at least three days after an earthquake when relatively more data are available, and the more data involved in fitting, the closer the estimated number to the actual figure. In terms of relative errors, the fitted result by modified exponential curve is more satisfactory than the result from exponential function. If death toll information with shorter time interval (e.g. 12 hours or even 6 hours) is available, we can make the estimation within a shorter period of time.

Death toll data fit for Chi-Chi, Kobe and Wenchuan earthquakes shows that modified exponential curve can satisfactorily describe the time history of death toll from an earthquake, which thereby provides references for 


\section{disaster relief headquarters in decision making.}

\section{References}

Christoskov L and Samardjieva E (1984). An approach for estimation of the possible number of casualties during strong earthquakes. Bulg Geophys $J$ 4: $94-106$.

Fu Z X and LI G P (1993). Research on earthquake casualty loss. Seismological Press, Beijing, 48 (in Chinese).

Gao J G and Jia Y (2005). A study on the time of promulgating earthquake disaster - an index of earthquake rescue ability. Journal of Catastrophology 20(1): 31-35 (in Chinese with English abstract).

Hong S Z (1995). Preliminary analysis of the time curve of disaster statistics of the earthquake occurring in the south of HYOGO Prefecture, Japan. Recent Developments in World Seismology (5): 10-14 (in Chinese).

Jia J P (2007). Statistics. China Renmin University Press, Beijing, 401-421 (in
Chinese).

Liu Z and Wu Z L (2006). A simple model of reported casualties during earthquakes and earthquake-generated tsunamis. Earthquake Research in China 21(4): 72-75 (in Chinese with English abstract).

Lomnitz C (1970). Casualties and behavior of populations during earthquakes. Bull Seism Soc Amer 60: $1309-1313$.

Samardjieva E and Oike K (1992). Modelling the number of casualties from earthquakes. Journal of Natural Disaster Science 14(1): 17-28.

Shi F Y (2006). Self-questioning and design of disaster medical assistance teams. http://www.etan.com.tw/ndmat/upload/disaster_handout/1_9. pdf.

Wang J L and Yang Z H (1997). Time history method to estimate seismic disasters. J Seism Res 20(4): 424-430 (in Chinese with English abstract).

Wyss M (2005). Human losses expected in Himalayan earthquakes. Natural Hazards 34(3): 305-314 